\title{
Using Life Cycle Assessment (LCA) to measure the environmental benefits of industrial symbiosis in an industrial cluster of SMEs
}

\author{
Tiberio Daddi ${ }^{\text {a, }}$, Benedetta Nucci ${ }^{a}$, Fabio Iraldo ${ }^{\text {a, b }}$ \\ a Sant'Anna School of Advanced Studies - Institute of Management, Piazza Martiri della Libertà 33, 56127, Pisa, Italy \\ ${ }^{\mathrm{b}}$ IEFE - Institute for Environmental and Energy Policy and Economics, Bocconi University, Milan, Italy
}

\section{A R T I C L E I N F O}

Article history:

Received 26 July 2016

Received in revised form

27 December 2016

Accepted 17 January 2017

Available online 18 January 2017

\section{Keywords:}

Life Cycle Assessment

Circular economy

Industrial cluster

Leather products

Industrial symbiosis

Tannery sector

\begin{abstract}
A B S T R A C T
Collaborative approach and infrastructures sharing are key industrial symbiosis initiatives adopted in clusters of SMEs. Several studies have dealt with the environmental benefits of industrial symbiosis however only a few have adopted a Life Cycle Assessment (LCA) to assess the benefits of these initiatives on the typical product of the cluster. Our paper presents the case of an Italian tannery cluster located in Tuscany. Through the calculation of an LCA with average data, our study compares the impact category results between two scenarios: the existing scenario where the IS initiatives are implemented and the other where these initiatives are less developed. The results show the positive contribution of these initiatives in several LCA impact categories such as climate change and terrestrial eutrophication.
\end{abstract}

ㄷ) 2017 Elsevier Ltd. All rights reserved.

\section{Introduction}

In the last hundred years, the shift from low to high levels of human development has led to an unprecedented increase in the use of natural resources. Driven initially by economic development in Europe and North America, and subsequently elsewhere, the world gross domestic product (GDP) has increased 25-fold since 1900 , leading to a 10 -fold increase in global resource extraction (Krausmann et al., 2009).

The circular economy (CE) represents a recent European solution to this issue. According to the EU circular economy policy acts (European Commission, 2014; European Commission, 2015), the economy should shift from a linear model based on productionconsumption-disposal towards a circular model, where the reuse of waste is maximised and the use of natural resources is reduced. A circular economy can bring significant economic and environmental benefits (Ellen MacArthur Foundation, 2015), which would contribute to achieving the European objectives set for the year 2020.

As a key concept of the circular economy, industrial symbiosis (IS) contributes to the achievement of these goals. Industrial

\footnotetext{
* Corresponding author.

E-mail address: tiberio.daddi@sssup.it (T. Daddi).
}

symbiosis has been widely discussed by several scholars over the last few years. Chertow et al. (2008) identified many types of collaborative arrangements for businesses that lead to the development ofit. In addition to the more "traditional" approach i.e. "byproduct exchanges" there are other typical approaches included by Chertow in the definition of IS, such as the sharing of utilities and infrastructures and joint provision of services. Chertow defines sharing utilities and infrastructures as the "pooled use and management of commonly used resources such as steam, electricity, water, and wastewater".

Several scholars have also raised the question of how to measure the environmental benefits of industrial symbiosis initiatives (Geng et al., 2009; Liu et al., 2009; Park et al., 2010; Yuan et al., 2006; Zhu et al., 2010). Life Cycle Assessment (LCA) is considered as one of the most important tools to achieve this aim (Eckelman and Chertow, 2013; Mattila et al., 2012; Sokka et al., 2011; Yu et al., 2014). (Scheepens et al., 2016). Although previous studies have focused on the application of LCA at the firm level, its application as average LCA data of a sample of companies located in the same industrial cluster and with a focus on the benefits of infrastructure sharing as part of industrial symbiosis has not been frequently studied.

Our paper aims to contribute to this field by assessing the infrastructures sharing initiatives adopted by an Italian industrial cluster in the tannery sector i.e. the tannery cluster of S.Croce 
sull'Arno (Tuscany, central Italy), one of the most important areas of leather production in Europe.

The paper is structured as follows. Section 2 focuses briefly on previous and recent studies published in the field of LCA and industrial symbiosis. In Section 3, we describe the case study, the research questions and illustrate the methods used to investigate those questions. In Sections 4 and 5 we present and discuss the results, and close the paper with some final remarks.

\section{Literature framework and research questions}

Among the variety of disciplines used to investigate industrial symbiosis (IS), LCA, represents an important tool to measure the environmental benefits achieved by IS initiatives, in some cases also at local level. For instance, in one of the papers on the application of LCAs to a local context (Dong et al., 2013), the authors assessed the carbon footprint of an entire industrial park in China. They highlighted the significant $\mathrm{CO}_{2}$ direct emissions of the companies located in the park as well as upstream and downstream emissions, and suggested policy actions to improve the $\mathrm{CO}_{2}$ emissions in specific sectors. Similarly, Singh et al. (2007) used an LCA to identify the best design of an eco-industrial park. The authors compared different designs and identified the potential trade-off in different environmental impact categories identified through an LCA. Boons et al. (2011) investigated how the term "industrial symbiosis" and "eco-industrial park", "industrial ecology" and "regional" are combined as one topic in the scientific literature. They concluded their paper by proposing a research agenda to investigate how institutional capacities evolve over time in regional industrial systems and how they affect the ecological impact of such systems.

On a wider geographical scale, Eckelman and Chertow (2009) used an LCA to quantify the benefits of waste reuse in the state of Pennsylvania. Collecting data from the Pennsylvania Department of Environmental Protection, they predicted wide-reaching potential environmental benefits from the reuse of waste in terms of energy savings and $\mathrm{CO}_{2}, \mathrm{NOx}$ and $\mathrm{SOx}$ emission reductions. Loiseau et al. (2014) dealt with what they called a "territorial LCA". They linked the territorial LCA to the European Directive (2001/42/EC) on Strategic Environmental Assessments. Applying their method to a French region (Bassin de Thau) of approximately $375 \mathrm{~km}^{2}$, they highlighted that the impacts on human health and ecosystem quality were higher for production than for consumption activities.

Other studies have dealt with the assessment of environmental services and infrastructures connected with significant industrial districts and areas, such as wastewater treatment plants or recovery plants.

Houillon and Jolliet (2005) used LCA to compare the impacts of six different wastewater treatment plants characterized by different sludge treatments. Considering the global warming impact, they proposed incineration in cement kilns as the best option. Similarly Suh and Rousseaux (2002) studied the sludge treatment options of five French wastewater treatment plants. The results of an LCA showed that the combination of anaerobic digestion and agricultural land application was the most environmentally friendly thanks to fewer emissions and less energy consumption.

Liu et al. (2011) applied an LCA to assess the benefits of energy recovery from municipal sewage sludge and re-refined oil combustion of the central heat-supply system of an eco-industrial park in China. The study showed significant environmental benefits in terms of a reduction in the global warming and eutrophication potential. Tong et al. (2013) assessed the benefits of a water reuse system in another industrial park in China. The results of their comparative LCA of different scenarios demonstrated the benefits of water reuse and showed that the reuse rate significantly affects the environmental performance of the system. Finally, Zhang et al. (2010) highlighted the benefits of a wastewater treatment and reuse project through a process-based LCA and input-output based LCA. The case study focused on a plant planned for the city of Xi'an (China) and considered the construction, operation and demolishing phases. The study showed that the life cycle benefits gained from treated wastewater reuse greatly surpassed the life cycle energy consumption.

The life cycle perspective has also been applied at the plant level to assess the environmental benefits in the tannery sector, for example the adoption of chromium-free tanning (Xu et al., 2015) or the production of biodiesel starting with tannery fleshings (Kiliç et al., 2014).

Our paper contributes to this literature by examining the contribution of industrial symbiosis initiatives adopted at a local level through LCAs. Based on the literature framework described above, the paper aims to answer the following questions:

RQ1: What kinds of environmental benefits are produced by infrastructures sharing initiatives adopted by an industrial cluster of SMEs grounded on the industrial symbiosis principles?

RQ2: Can these benefits be measured with an LCA perspective? How do these industrial symbiosis initiatives positively influence the impact categories of the cluster representative product (i.e. finished leather)?

The novelty of our paper lies in the approach adopted. First, the paper focuses on assessing the positive impact of IS actions in an entire industrial cluster of SMEs. The benefits are highlighted by considering the sum of positive influences that different actions have had on the typical product of the cluster defined as the functional unit of the LCA: $1 \mathrm{~m}^{2}$ of finished leather. Second, the paper assesses the life cycle environmental benefits of an important new water reuse project within the cluster in order to support the decisions of local key actors regarding the related investment choices. This second approach uses the LCA as support for the local decision makers.

\section{Case study profile and methods}

\subsection{The geographical context}

Our case study refers to a cluster of tanneries located in S.Croce sull'Arno in Tuscany, Italy. The cluster covers an area of about $240 \mathrm{~km}^{2}$ with 100,000 inhabitants, and includes six municipalities (i.e. local authorities) (Daddi et al., 2015). This cluster is one of the most important areas in the field of leather production both in Italy and abroad. In fact, Italy accounts for $66 \%$ of the EU's production of tanned leather. S.Croce sull'Arno is the largest tannery cluster in Italy, providing $35 \%$ of the Italian production of tanned leather and $98 \%$ of the Italian production of sole leather. The first tanneries date back to the mid 1800s. After the end of the Second World War, the industry expanded and became part of the urban fabric of the district. This area has always been traditionally linked with the tanning of raw hide (UNIC, 2015).

In the cluster there are about 600 companies operating in the tanning sectors with a total of around 6000 employees. The majority of companies has fewer than 12 employees. The annual turnover is about 2000 million euros of which $70 \%$ derives from the exports of finished leather. The largest final destination of the finished leather produced in S.Croce sull'Arno is the shoe sector (UNIC, 2015).

For the last 20 years, both the private and public actors in the cluster have been very much aware of sustainability (Daddi et al., 2015). In fact, the tanning process is one of the most polluting manufacturing processes. It has always been associated with 
odours and other impacts on air, surface and ground water and solid waste. Local communities have also showed a high awareness of environmental issues. In some cases, the tanneries are very close to residential areas thus leading to conflicts and complaints. This situation has made entrepreneurs more aware of the environment as an important variable in terms of company management.

The cluster has also experienced strong economic pressures. S.Croce sull'Arno is one of the most important areas supplying the Italian and international fashion sectors. Brands like Gucci, Ferragamo, Versace, Dolce \& Gabbana, Burberry, and Hugo Boss have important suppliers in the cluster for the production of their leather shoes and bags. In the last few years these customers have adopted strong environmental policies in managing the supply chain requiring tanneries to adopt management as well as technological actions to improve the environmental performance of the products.

All these aspects have contributed to raise the environmental awareness of entrepreneurs. This provided a fertile terrain to collect data for LCAs and to carry out our research.

\subsection{Method}

This study assesses the life cycle environmental benefits of the IS initiatives implemented in the industrial cluster of small and medium enterprises (SMEs) of S.Croce sull'Arno (Italy). Previous studies have highlighted how SMEs face barriers in the adoption of these initiatives (Andersen, 1997). Following Chertow's definition (see Sect. 1) we use the term 'industrial symbiosis initiatives', to mean the collective plants that have been established in a cooperative way by the SMEs located in the cluster. The initiatives considered in the study are waste recovery plants and collective wastewater treatment plants aimed at improving the environmental performance of the whole cluster by collectively managing the tannery emissions. We considered the following collective services:

- Aquarno wastewater treatment plant: a public-private consortium consisting of a majority of private companies and the body which manages the $\mathrm{S}$. Croce sull'Arno water treatment plant. Yearly the plant receives about $3,600,000 \mathrm{~m}^{3}$ of industrial wastewater and about $1,000,000 \mathrm{~m}^{3}$ of urban wastewater;

- Ecoespanso plant (sludge recovery plant): a mixed private and public company, with a majority of private shareholders. The main aim of the plant is to recover the sludge of the Aquarno wastewater treatment plant that flows through a specific pipeline. The treatment capacity totals about 100-120,000 tons per year, and the treated sludge is recovered as inert material;

- Consorzio Recupero Cromo Spa (chromium recovery plant): a private company composed of 240 member tanning companies from all over the district. These companies send exhaust chrome liquor to the consortium for chrome extraction. The recovered chrome is returned to the original companies, which use it directly in tanning processes. This plant can produce over $21,000 \mathrm{~kg}$ of basic chrome sulphate per day;

- Consorzio S.G.S. Spa (shaving and fleshing waste recovery plant): a private company composed of 230 member tanneries. This plant recovers the fleshings, and extracts the fat and protein which is then sold. The plant employs a staff of 50 and processes 70,000 tons of fleshings per year;

- Cuoiodepur wastewater treatment plant: a second wastewater treatment plant which receives about $1,700,000 \mathrm{~m}^{3}$ of industrial water emissions per year and recovers its sludge as fertilizers. It is a public-private consortium composed of 155 member companies, and the Municipality of San Miniato is a shareholder. It employs 40 people.
All these "cooperative" initiatives have been developed in the last thirty years, some of them also before the birth of the first definitions of industrial ecology and industrial metabolism (Frosch and Gallopoulos, 1989). In addition, these initiatives have started without a specific local policy and without a coordinative function. This self-organizing system did not attempt to follow a specific symbiosis model nor was fully conscious of the collective environmental benefits being gained. For these reasons, the case of S. Croce sull'Arno can be also classified as "uncovered" industrial symbiosis (Chertow, 2007).

We developed an average LCA data focused on a representative product (i.e. an "average" product based on the input data from a representative sample of tanneries) on the following functional unit: $1 \mathrm{~m}^{2}$ of finished leather from the industrial cluster. The environmental impacts connected to the functional unit are calculated by considering the benefit for the tanneries of being or not being part of the environmental infrastructures sharing initiatives. We calculated and compared the results of the LCA of the two different scenarios (Fig. 1): Scenario 1) where industrial symbiosis initiatives are implemented (i.e. the current scenario), and Scenario 2) a hypothetical scenario where industrial symbiosis initiatives are less adopted.

In order to estimate Scenario 2 and to make this estimation realistic, we took into account the real situations of the other two main important Italian tannery clusters located in Veneto (Arzignano) and Campania (Solofra). We found that some initiatives such as the sludge recovery system, the chromium collective recovery plant and the shavings and fleshings waste collective recovery plant are particular features of the S.Croce sull'Arno cluster. Thus, in order to develop Scenario 2, we eliminated these initiatives (Figs. 2 and 3).

The analysis was conducted with an LCA based on ISO standards 14040:2006 and 14044:2006. Following Mattila et al. (2012), the study described in this work can be classified both as an industrial symbiosis study focused on the analysis (accounting) of the environmental impacts (group 1) and on the identification of improvement options (group 2).

In addition to the comparison between scenarios 1 and 2 a further scenario has been assessed. During the research, local policy makers were interested in the quantification of the environmental benefits of a future collective approach project. In particular, they are planning to set up a system in the cluster that would reuse the water discharged by one of the wastewater treatment plants in the tanneries in order to reduce the consumption from wells. They had two different objectives in term of water reuse, so we codified these two objectives naming them as scenarios $3 \mathrm{a}$ and scenario $3 \mathrm{~b}$ and the environmental benefits of the impact categories "water depletion" were calculated.

As previously mentioned, the functional unit of this study is an average of $1 \mathrm{~m}^{2}$ of tanned leather produced in the cluster of S.Croce sull'Arno. Unlike other works focused on the environmental impacts of industrial symbiosis systems, where the functional unit of the system is taken as equal to the total annual production of the symbiosis (Sokka et al., 2011), here the functional unit refers to the main product of the district. This decision was taken in order to easily integrate the LCA results into local policies and facilitate communication with the main stakeholders related to the reduction in the potential environmental impact of the entire system.

The system boundaries are defined as follows: from rearing the animals to the tannery gate. All the activities performed to produce tanned leather are included in the system boundaries, such as farming, slaughterhouse activities, preservation of hides and skins, tanning, and all the transportation required in all the stages of the life cycle. All the activities connected to the tanning process, such as wastewater treatments and waste treatments are also included 


Calculate an average LCA data of a representative $\mathrm{m}^{2}$ of finished leather of the industrial cluster in
the current situation (SCENARIO 1)
- Identify the LCA impact categories values of SCENARIO 1
developed or not present

Fig. 1. The five steps of the method.

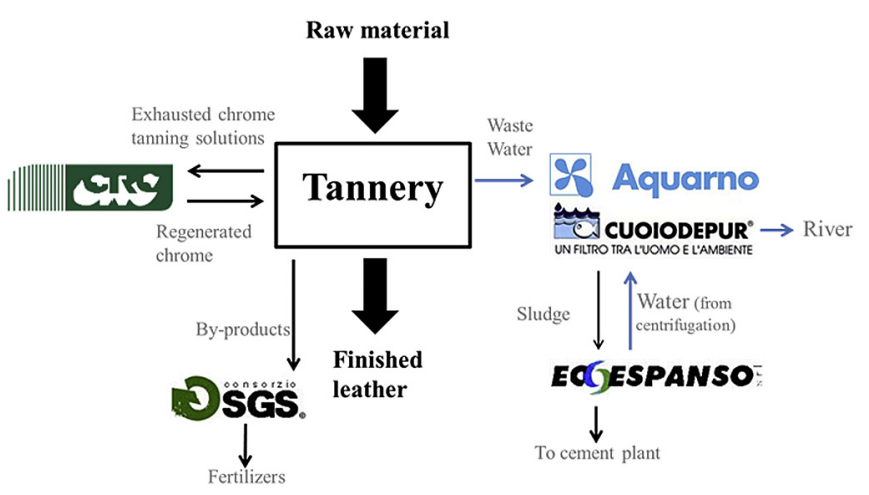

Fig. 2. Scenario 1. inside the system boundaries. In the analysis of scenario 1, one important issue is the allocation of the impacts to by-products/coproducts. There are two main approaches to by-product/co-product allocation used in LCAs (Mattila et al., 2012):

- partitioning, where the inventory data and the impacts are partitioned among the products by an allocation key;

- system expansion, which considers what production is replaced by the use or supply of the by-product, and this replacement is credited to the system studied.

In this work, the attributional system expansion approach as described by Mattila et al. (2012) was applied to all the by-products of the tanning process and the waste and wastewater treatment plants. The method used for the impact assessment was the International Reference Life Cycle Data System (ILCD) and related characterization.

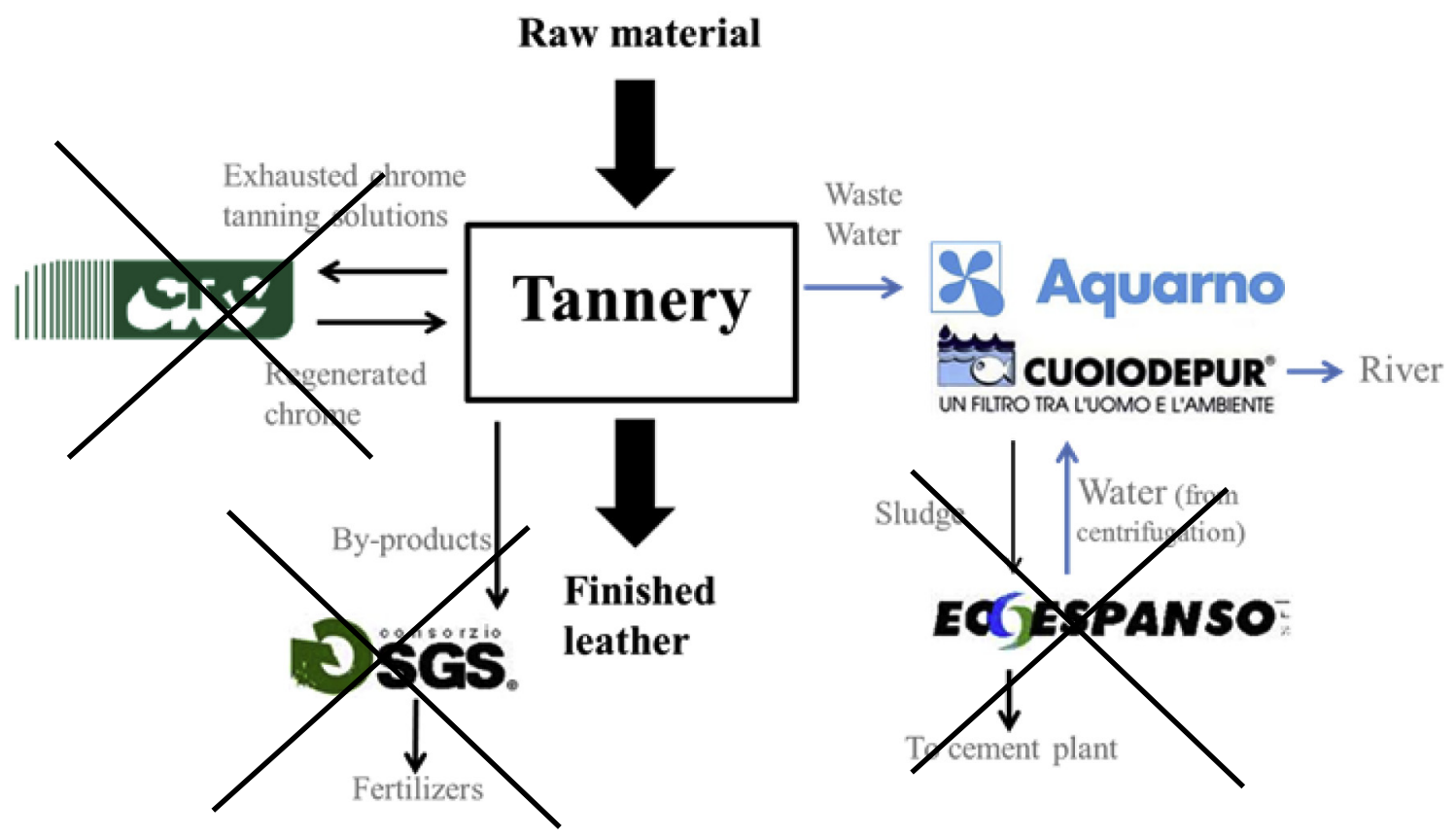

Fig. 3. Scenario 2 . 


\subsection{Sample and data collection}

The average LCA data was calculated considering a representative group of tanneries located in the S.Croce sull'Arno cluster. Cluster-LCA is based on the possibility that some factors that are common to a particular group of firms enable a "collective" LCA study to be created, from which the firms can later draw different benefits. This approach is appropriate when the group of firms is sufficiently homogeneous for the synergic application of the LCA method and the creation of a "shared" LCA (Daddi et al., 2015). Past experiences have demonstrated how a cooperative application of environmental management tools can overcome the barriers experienced by SMEs, such as a lack of resources and knowledge (Tessitore et al., 2014; Daddi and Iraldo, 2016).

Data were collected in 2014, using 2013 data from tanneries, wastewater treatment plants and plants that perform the recovery of waste from the tanning process, all located in the tanning S.Croce sull'Arno cluster. The collected data were used to constitute the average inventory for $1 \mathrm{~m}^{2}$ of leather produced in the district, which enables the environmental impact of an average $\mathrm{m} 2$ of leather to be calculated.

Secondary data were taken from commercial LCA databases, above all the Ecoinvent database in its last release, and were used for the production of the raw materials used in the process.

Data were collected from 22 tanneries in the district which produced a total of $6,300,104 \mathrm{~m}^{2}$ of tanned leather representing approximately $14 \%$ of the production in the cluster and $5 \%$ of the Italian production in 2013 (See Table 1). The next Fig. 4 indicates the boundaries of our LCA study.

\section{Results and discussion}

The results of the average LCA data on the representative product are reported in Table 2. The impact categories analyzed are those listed in the PCR of the International EPD System for "finished bovine leather". As shown in the table, the IS initiatives improved all the environmental impact categories considered by the assessment method. The main environmental benefits were achieved in the "climate change" impact category, with an improvement of $21.87 \%$ and an absolute reduction of approximately $4.3 \mathrm{~kg}$ of $\mathrm{CO}_{2}$ equivalent per $\mathrm{m}^{2}$ of finished leather. The fact that the tannery cluster produces approximately 45 million $\mathrm{m}^{2}$ of finished leather clearly highlights the potential role of the industrial symbiosis initiatives in pursuing the mitigation of global warming. The second most improved impact category was terrestrial eutrophication, with an improvement of $18.51 \%$. Even if to a lesser extent, we can say that in this case study there was a general improvement in the environmental performance thanks to the IS initiatives: six other impact categories improved from $10 \%$ to $20 \%$. Table 2 reports the results related to all the impact categories.

These results provide a clear answer to our first research question and highlight how the collaborative efforts of the cluster actors carried out over the past few years have improved the environmental performance of the cluster representative product,

Table 1

Number of companies in the sample.

\begin{tabular}{ll}
\hline Tanneries & $\mathbf{2 2}$ \\
Chrome tanning & 7 \\
Vegetable tanning & 4 \\
Other tanning processes & 2 \\
Sub-contractors & 5 \\
Plants linked with circular economy initiatives & $\mathbf{5}$ \\
Waste water treatment plant & 2 \\
Waste recovery and treatment & 3 \\
\hline
\end{tabular}

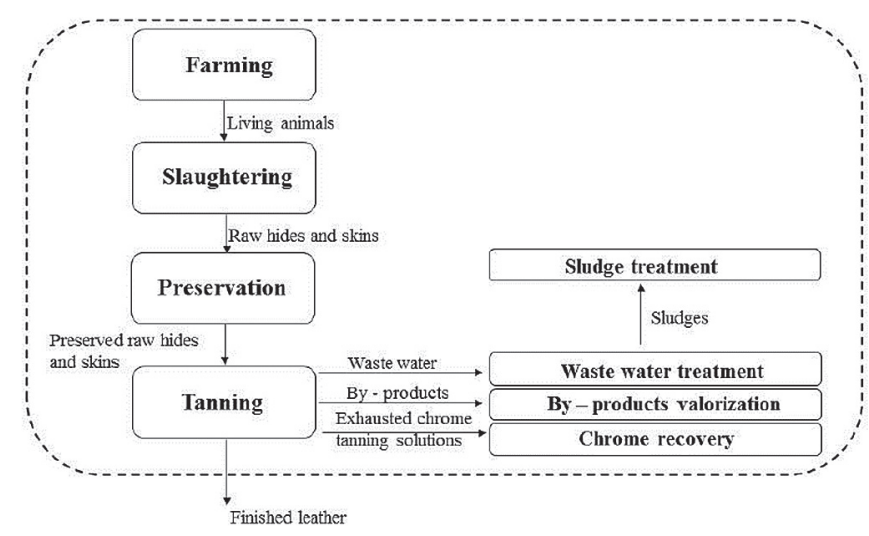

Fig. 4. LCA study boundaries.

considered in a life-cycle perspective.

As anticipated in paragraph 3.2, the same model was also used to assess the potential environmental effects of some planned improvement actions referred to some water re-use initiatives to be adopted at the cluster level. Two different new scenarios were assessed, both related to the recovery of water from the wastewater treatment plant to be recycled by the tanneries for the production process:

- scenario 3a: recovery of $20 \%$ of the wastewater discharged by the wastewater treatment plant which is re-used by the tanneries.

- scenario 3b: recovery of $40 \%$ of the wastewater discharged by the wastewater treatment plant which is re-used by the tanneries.

The project is still in the design phase, thus the local actors involved in the investment have not yet clarified the total amount of water that will be re-used. As shown in Table 2, the infrastructure-sharing initiatives already implemented have not improved the water footprint much, yielding a reduction of "only" $1.75 \%$.

We thus calculated the improvement of the impact category "water resource depletion" according to both improvement options (Table 3).

As shown in Table 3, the re-use of water of the wastewater treatment plant in the tanneries will not lead to a significant improvement in the water footprint. This indicates that, although $40 \%$ of the discharge volume of the wastewater treatment plant is a high figure in absolute terms, in the life cycle of the finished leather there are other upstream processes that have definitely a greater impact on the water footprint.

The improvements achieved in scenario 1 concern all the impact categories and, in most cases, were above $10 \%$ compared to scenario 2 where no IS initiative was undertaken, proving that the contribution to the environmental footprint has been significant. In addition, no impact category indicator showed a worsening with respect to the scenario 2 , clearly indicating that the cluster cooperative approach in this case produces relevant positive results.

We should emphasize that the IS initiatives analyzed in this paper were carried out in the past and prompted by two kinds of main motivations. On the one hand, the local industrial system was aimed at creating synergies and developing common resources. The main aim was to save time and money in managing the key environmental aspects connected to the local tanning processes. This means that the main driver for the initiatives was not the willingness to improve the environmental footprint of the cluster 
Table 2

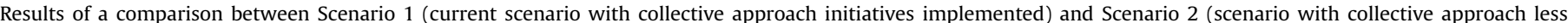
developed).

\begin{tabular}{|c|c|c|c|c|}
\hline \multirow[t]{2}{*}{ Impact category } & \multirow[t]{2}{*}{ Unit } & \multicolumn{2}{|c|}{ Unit: $1 \mathrm{~m}^{2}$ finished leather } & \multirow[t]{2}{*}{ Difference } \\
\hline & & Scenario 1 & Scenario 2 & \\
\hline Climate change & $\mathrm{kg} \mathrm{CO} 2 \mathrm{eq}$ & 15.34 & 19.64 & $-21,87 \%$ \\
\hline Ozone depletion & kg CFC-11 eq & $9.32 \mathrm{E}-06$ & $9.46 \mathrm{E}-06$ & $-1,48 \%$ \\
\hline Human toxicity, non-cancer effects & CTUh & $9.40 \mathrm{E}-06$ & $9.67 \mathrm{E}-06$ & $-1,48 \%$ \\
\hline Human toxicity, cancer effects & CTUh & $6.147 \mathrm{E}-06$ & $6.61 \mathrm{E}-06$ & $-7,00 \%$ \\
\hline Particulate matter & kg PM2.5 eq & 0.0121 & 0.0143 & $-15,38 \%$ \\
\hline Ionizing radiation $\mathrm{HH}$ & $\mathrm{kBq} U 235$ eq & 0.846 & 0.941 & $-10,10 \%$ \\
\hline Ionizing radiation $\mathrm{E}$ (interim) & CTUe & $6.75 \mathrm{E}-06$ & 7.52E-06 & $-10,24 \%$ \\
\hline Photochemical ozone formation & kg NMVOC eq & 0.06092 & 0.07072 & $-13,86 \%$ \\
\hline Acidification & molc $\mathrm{H}+\mathrm{eq}$ & 0.19002 & 0.21517 & $-11,69 \%$ \\
\hline Terrestrial eutrophication & molc $N$ eq & 0.38306 & 0.47014 & $-18,52 \%$ \\
\hline Freshwater eutrophication & $\mathrm{kg} P$ eq & 0.00160 & 0.00182 & $-12,09 \%$ \\
\hline Marine eutrophication & $\mathrm{kg} \mathrm{N}$ eq & 0.04686 & 0.05014 & $-6,54 \%$ \\
\hline Freshwater ecotoxicity & CTUe & 85.11 & 92.17 & $-7,66 \%$ \\
\hline Land use & $\mathrm{kg} \mathrm{C}$ deficit & 132.57 & 138.97 & $-4,61 \%$ \\
\hline Water resource depletion & m3 water eq & 0.80887 & 0.82329 & $-1,75 \%$ \\
\hline Mineral, fossil \& ren resource depletion & $\mathrm{kg} \mathrm{Sb}$ eq & 0.01808 & 0.01837 & $-1,58 \%$ \\
\hline
\end{tabular}

Table 3

Water footprint improvements achievable with the new investments in the reuse of water.

\begin{tabular}{|c|c|c|c|c|c|}
\hline \multirow[t]{2}{*}{ Impact category } & \multirow[t]{2}{*}{ Unit } & \multicolumn{3}{|c|}{ Unit: $1 \mathrm{~m}^{2}$ finished leather } & \multirow[t]{2}{*}{ Difference (scenario $1 /$ scenario $3 b$ ) } \\
\hline & & Scenario 1 & Scenario $3 a$ & Scenarion $3 b$ & \\
\hline Water resource depletion & m3 water eq & 0.80887 & 0.79779 & 0.78669 & $-2.74 \%$ \\
\hline
\end{tabular}

product, but a twofold objective.

The first objective was to create a technical solution for the abatement of pollutants and the recovery of waste and secondary materials for SMEs (which traditionally face barriers in terms of lack of resources) at reasonable costs.

The second objective was to tackle environmental problems at a local level, i.e. affecting the local environment and not taking into consideration the categories of impacts related to global or transnational/regional problems (e.g. global warming, acid rain). This is a typical situation in cluster approaches to environmental management as well as in industrial symbiosis projects. In most cases the focus is on the ecosystem that is directly affected by the cluster or the local production. No or limited attention is paid to the impact categories of a higher level, thus giving rise to a "pollution transfer" or "cross media effects" that improve the specific local conditions of the environment but worsen the impacts elsewhere. These tradeoffs are often an undesired side-effect of cluster approaches.

This has several implications for policy makers. Firstly, our study highlights that policymakers should exploit cluster approaches if they want to promote industrial symbiosis, insofar as this guarantees an optimisation of the environmental improvement actions, both at the local and regional/global levels. The shared resources and the common services implemented at S.Croce have led to an absolute improvement with respect to similar scenarios where the same actions were not developed.

Secondly, our study demonstrates the utility of supporting cluster-driven actions to promote industrial symbiosis by an LCAbased method. The LCA is able to identify (and possibly magnify) the advantages and benefits of the common resources and services for the different impact categories concerning the regional and global environment. Policy makers will thus be able to justify their decisions and to demonstrate the commitment of the cluster industrial system to contribute to sustainable development.

Thirdly, our study has implications for the managers operating in companies (presumably SMEs) that are located in a cluster. In fact, our results provide empirical evidence that by pursuing collective actions with a cluster approach, in addition to a higher efficiency, companies can also benefit from positive outcomes connected to the improvement in the environmental footprint of their products. Co-operating in a cluster by sharing economic, technical and organisational resources and using common infrastructures and services can be a competitive strategy to enhance the competitiveness of the product from a "green marketing" prospect.

The co-ordinated action of all the services that we have assessed in our model yields better environmental performance for all the impact categories. This implies that managers in a cluster can develop a common strategy to improve their reputation and image by proposing a greener product on the market, supported by the results of an LCA-based approach. The manager of a cluster-SME can take advantage of the "industrial symbiosis" options by grounding the competitive strategy of its company on the advantages derived from a lower environmental footprint.

Managers can also adopt an LCA (as shown above) as a tool to support investments in further strengthening the cluster approach by adopting innovative technologies and shared solutions to environmental problems. This would enable them to assess the costs and benefits of a life-cycle perspective, and not just to optimise the efficiency and solve local environmental problems.

Finally, managers of cluster-SMEs could exploit the opportunities of the cluster approach to fuel their R\&D and product design. As is well known, SMEs generally suffer from a lack of resources and a low tendency to adopt a strategic approach. This is especially the case in some functions of the organization, which are commonly regarded as being a prerogative of companies with huge resources (e.g. large multinational corporations or innovation leaders who are front-runners in the various industrial sectors). By relying on the results of an average LCA data to focus on cluster-oriented solutions, SME managers could overcome the barriers that traditionally hamper their R\&D and innovative design strategies, and thus be more competitive on the market (Testa et al., 2016). 


\section{Conclusions}

This work has demonstrated the potential benefits derived from the use of an LCA for the assessment of the impact of a complex system of infrastructure sharing initiatives. The study highlights how the collective approach adopted in the cluster of SMEs allows to achieve relevant environmental benefits. Positive answers to the two research questions have been identified and LCA allowed to measure improvements of several impact categories of the cluster representative product (i.e. finished leather) such as carbon footprint, terrestrial eutrophication and particular matter.

This outcome of the study has important implications, both at policy and managerial levels.

Firstly, our study highlights that policymakers should exploit cluster approaches if they want to promote industrial symbiosis, insofar as this can guarantee an optimisation of the environmental improvement actions, as the tanning cluster of S.Croce sull'Arno shows. The shared resources and the common services implemented at S.Croce sull'Arno have led to an absolute improvement if compared to similar scenarios where the same actions were not developed.

Secondly, our study demonstrates the potential utility of supporting cluster-driven actions to promote industrial symbiosis by an LCA-based method. The LCA is able to identify (and possibly magnify) the advantages and benefits of the common resources and services for the different impact categories concerning the regional and global environment. Policy makers will thus be able to justify their decisions and to demonstrate the commitment of the cluster industrial system to contribute to sustainable development.

Thirdly, our case-study has implications for the managers operating in companies (presumably SMEs) that are located in a cluster. In fact, the results that were achieved by the tanneries in S.Croce sull'Arno provide empirical evidence that by pursuing collective actions with a cluster approach, in addition to a higher efficiency, companies can also benefit from positive outcomes connected to the improvement in the environmental footprint of their products. Therefore, for SMEs co-operating in a cluster by sharing economic, technical and organisational resources and using common infrastructures and services, can be a competitive strategy to enhance the competitiveness of the product from a "green marketing" prospect.

The co-ordinated action of all the services that we have assessed in our model yields better environmental performance for all the impact categories. This implies that managers in a cluster can develop a common strategy to improve their reputation and image by proposing a greener product on the market, supported by the results of an LCA-based approach. The manager of a cluster-SME can take advantage of the "industrial symbiosis" options by grounding the competitive strategy of its company on the advantages derived from a lower environmental footprint.

Managers can also adopt an LCA (as shown above) as a tool to support investments in further strengthening the cluster approach by adopting innovative technologies and shared solutions to environmental problems. This would enable them to assess the costs and benefits of a life-cycle perspective, and not just to optimise the efficiency and solve local environmental problems.

Finally, managers of cluster-SMEs could exploit the opportunities of the cluster approach to fuel their R\&D and product design. As is well known, SMEs generally suffer from a lack of resources and a low tendency to adopt a strategic approach. This is especially the case in some functions of the organization, which are commonly regarded as being a prerogative of companies with huge resources (e.g. large multinational corporations or innovation leaders who are front-runners in the various industrial sectors). By relying on the results of an average LCA data to focus on cluster-oriented solutions, SME managers could overcome the barriers that traditionally hamper their R\&D and innovative design strategies, and thus be more competitive on the market (Testa et al., 2016).

There are three types of limitations of our study, which are partially related to the complexity of the system, and the complexity/maturity of LCAs and their application.

An industrial cluster system is very complex, data collection is very difficult since it involves a huge number of actors. In addition aggregated data at the system level are scarce but still need to be collected. The second type of limitation is linked to the impact assessment method. Current impact assessment methods do not easily take into account the effects of the release of some pollutants into the water system. For example, the effect of Cl-, SO42- is disregarded by current methods and the effect of COD is not included as the value of these groups of pollutants has not been included in the model. For this reason, the beneficial effect of the recovery of water as reported in this work is underestimated. The only beneficial effect is linked to the reduction of water wells used by tanneries, but not the beneficial effects on the output side, for example the reduction in the amount of pollutants released in the water. Finally, even if some of the conclusions obtained by our case-study can be generalized and considered valid also for similar cases, others are influenced by the specific features of S.Croce sull'Arno cluster and for that reason the validity for other contexts should be demonstrated.

In terms of future works, it would be interesting to use the approach used in our study to understand the economic and social effects of the described initiatives. A Life Cycle Costing (LCC) could be performed to identify the economic added value provided by the IS initiatives. In addition, future research could entail calculating the environmental impact of the entire circular economy system, using the total annual production of the symbiosis as the functional unit and comparing it with a system that yields the same product mix. At the moment, much effort is devoted to collecting the data needed to accurately identify the product mix of the district. Although this task is simple when the system is composed of just a few units (e.g. a handful of companies), in the case of a real industrial district where the principles of circular economy and industrial symbiosis are applied, this becomes very difficult to assess due to the high number of businesses and interchanges of waste and products that take place.

\section{References}

Andersen, O., 1997. Industrial ecology and some implications for rural SMEs. Bus. Strategy Environ. 6, 146-152.

Boons, F., Spekkink, W., Mouzakitis, Y., 2011. The dynamics of industrial symbiosis: a proposal for a conceptual framework based upon a comprehensive literature review. J. Clean. Prod. 19, 905-911.

Chertow, M.R., 2007. “Uncovering” industrial symbiosis. J. Indus. Ecol. 11, 11-30.

Chertow, M.R., Ashton, W.S., Espinosa, J.C., 2008. Industrial symbiosis in Puerto Rico: environmentally related agglomeration economies. Reg. Stud. 42, 1299-1312.

Daddi, T, Iraldo, F, 2016. The effectiveness of cluster approach to improve environmental corporate performance in an industrial district of SMEs: a case study. Int. J. Sustain. Dev. World Ecol. 23, 163-173.

Daddi, T., Nucci, B., Iraldo, F., Testa, F., 2015. Enhancing the adoption of life cycle assessment by small and medium enterprises grouped in an industrial cluster: a case study of the tanning cluster in Tuscany (Italy). J. Ind. Ecol. 20 (5), 1199-1211. http://dx.doi.org/10.1111/jiec.12379 published online.

Dong, H., Geng, Y., Xi, F., Fujita, T., 2013. Carbon footprint evaluation at industrial park level: a hybrid dife cycle assessment approach. Energy Policy 57, 298-307.

Eckelman, M.J., Chertow, M.R., 2013. Life cycle energy and environmental benefits of a US industrial symbiosis. Int. J. Life Cycle Assess. 18, 1524-1532.

Eckelman, M.J., Chertow, M.R., 2009. Quantifying life cycle environmental benefits from the reuse of industrial materials in Pennsylvania. Environ. Sci. Technol. 43, 2550-2556.

Ellen MacArthur Foundation, 2015. Growth Within: a Circular Economy Vision for a Competitive Europe. https://www.ellenmacarthurfoundation.org/publications.

European Commission, 2014 COM, 2014. 398 final. Communication from the Commission to the European Parliament, the Council, the European Economic 
and Social Committee and the Committee of the Regions. Towards a Circular Economy: a Zero Waste Programme for Europe. Brussels, 2015.

European Commission, 2015 COM, 2015. 614 final. Communication from the Commission to the European Parliament, the Council, the European Economic and Social Committee and the Committee of the Regions. Closing the Loop - an EU Action Plan for the Circular Economy. Brussels, 2015.

Frosch, R.A., Gallopoulos, N.E., 1989. Strategies for manufacturing. Sci. Am. 261, $144-152$.

Geng, Y., Zhu, Q., Doberstein, B., Fujita, T., 2009. Implementing China's circular economy concept at the regional level: a review of progress in Dalian, China. Waste Manag. 29, 996-1002.

Houillon, G., Jolliet, O., 2005. Life cycle assessment of processes for the treatment of wastewater urban sludge: energy and global warming analysis. J. Clean. Prod. 13, 287-299.

Krausmann, F.S., Gingrich, N., Eisenmenger, K.H., Erb, H., Haberl, FischerKowalski, M., 2009. Growth in global materials use, GDP and population during the 20th century. Ecol. Econ. 68, 696-705.

Kiliç, E., Puig, R., Baquero, G., Zengin, G., 2014. Carbon footprint and energy balance of biodiesel produced from tannery fleshings. J. Am. Leather Chem. Assoc. 109, 296-305.

Liu, Q., Li, H., Zuo, X., Zhang, F., Wang, 2009. A survey and analysis on public awareness and performance for promoting circular economy in China: a case study from Tianjin. J. Clean. Prod. 17, 265-270.

Liu, Q., Jiang, P., Zhao, J., Zhang, B., Bian, H., Qian, G., 2011. Life cycle assessment of an industrial symbiosis based on energy recovery from dried sludge and used oil. J. Clean. Prod. 19, 1700-1708.

Loiseau, E., Roux, P., Junqua, G., Maurel, P., Bellon-Maurel, V., 2014. Implementation of an adapted LCA framework to environmental assessment of a territory: important learning points from a French Mediterranean case study. J. Clean. Prod. 80, 17-29.

Mattila, T., Lehtoranta, S., Sokka, L., Melanen, M., Nissinen, A., 2012. Methodological aspects of applying life cycle assessment to industrial symbioses. J. Indus. Ecol. $16,51-60$.

Park, J., Sarkis, J., Wu, Z., 2010. Creating integrated business and environmenta value within the context of China's circular economy and ecological modernization. J. Clean. Prod. 18, 1494-1501.
Scheepens, A.E., Vogtlaender, J.G., Brezet, J.C., 2016. Two life cycle assessment (LCA) based methods to analyse and design complex (regional) circular economy systems. Case: making water tourism more sustainable. J. Clean. Prod. 114, 257-268.

Singh, A., Lou, H.H., Yaws, C., Hopper, L., Pike, R.W., 2007. Environmental impact assessment of different design schemes of an industrial ecosystem. Resour. Conser. Recycl. 51, 294-313.

Sokka, L., Lehtoranta, S., Nissinen, A., Melanen, M., 2011. Analyzing the environmental benefitts of industrial symbiosis life cycle assessment applied to a Finnish forest industry complex. J. Indus. Ecol. 15, 137-155.

Suh, Y.J., Rousseaux, P., 2002. An LCA of alternative wastewater sludge treatmen scenarios. Resources. Conser. Recycl. 35, 191-200.

Tessitore, S., Testa, F., Daddi, T., Iraldo, F., 2014. The cluster approach as a solution to improve environmental management at SMEs level: a comparison study. Environ. Eng. Manag. J. 13, 1827-1838.

Testa, F., Nucci, B., Tessitore, S., Iraldo, F., Daddi, T., 2016. Perceptions on LCA implementation: evidence from a survey on adopters and nonadopters in Italy. Int. J. Life Cycle Assess. 21, 1501-1513.

Tong, L., Liu, X., Yuan, Z., Zhang, Q., 2013. Life cycle assessment of water reuse systems in an industrial park. J. Environ. Manag. 129, 471-478.

UNIC (Unione NAzionale Industrial Conciaria), 2015. Rapporto di Sostenibilità 2015 Milano available from: www.unic.it.

Xu, X., Baquero, G, Puig R., Shi, J. Sang J., Lin, W., 2015. Carbon footprint and toxicity indicators of alternative chromium-free tanning in China. J. Am. Leather Chem. Assoc. 110, 130-137.

Yu, F., Han, F., Cui, Z., 2014. Assessment of life cycle environmental benefits of an industrial symbiosis cluster in China. Environ. Sci. Pollut. Res. 22, 5511-5518.

Yuan, Z., Bi, J., Moriguichi, Y., 2006. The circular economy: a new development strategy in China. J. Indus. Ecol. 10, 4-8.

Zhang, Q.H., Wang, X.C., Xiong, J.Q. Chen, R., Cao, B., 2010. Application of life cycle assessment for an evaluation of wastewater treatment and reuse project - case study of Xi'an. China Bioresour. Technol. 101, 1421-1425.

Zhu, Q., Geng, Y., Lai, K.-H., 2010. Circular economy practices among Chinese manufacturers varying in environmental-oriented supply chain cooperation and the performance implications. J. Environ. Manag. 91, 1324-1331. 